\title{
تأثير طرق التبييض المنزلية على الخواص الطبيعية والميكانيكية للأقمشة القطنية
}

\author{
إعداد

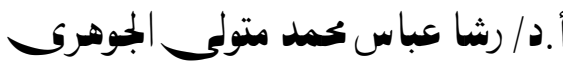 \\ أستاذ الملابس و النسيج بقسم الأقتصاد المنزلى لئى \\ هلدير محمد محمد علمــل أبو العز \\ رؤوفة محمد مسعد الجمل \\ نورا سمير الهادى عبد| لحميد \\ الزهر| أزمد المرسمسل عبده \\ حسناء السيد سعد محمد \\ دعاء عبد|لر|فح الششتاوكى نصير \\ داليا رباض محمد أبو زيد
}

مجلة بحوث التربية النوعية ـ جامعة المنصورة

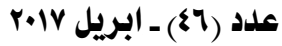




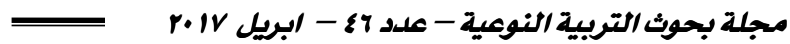

تأثير طرق التبييض المنرلية على الخواص الطبيسية والميكانيكية

للأققمشة القطنية

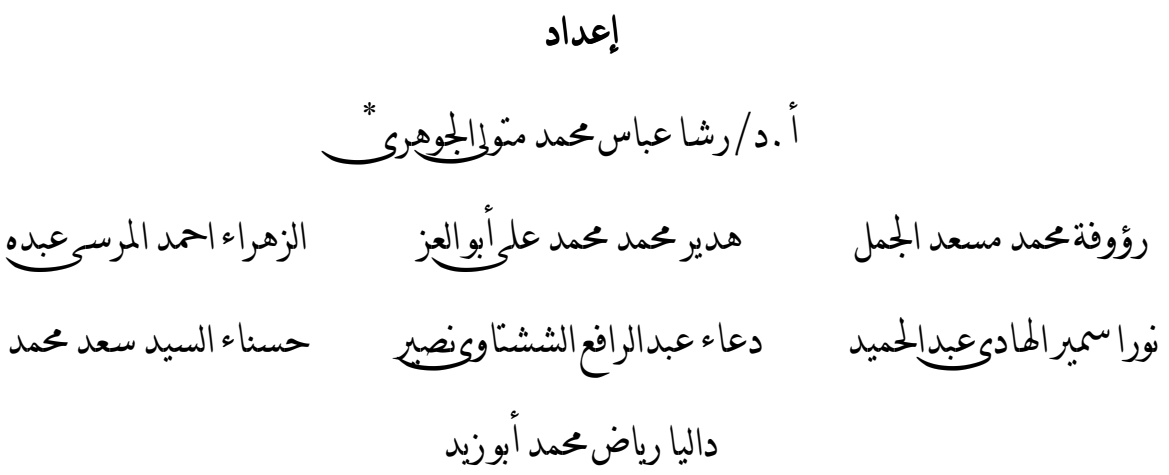

هلخص البحث

يهدف البحث إلى التوصل إلى أفضل مـادة تبيض موجودة فى السوق المحلى (موضـع البحثى)

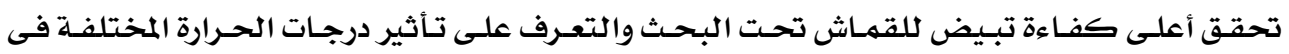

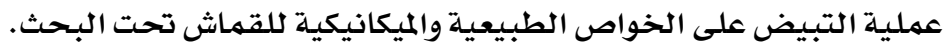
وبعد إجراء التحليل الأحصائى كانت أهم النتائج كما يلى :

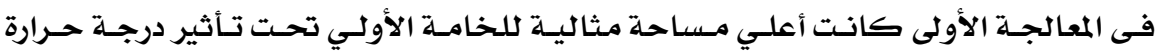

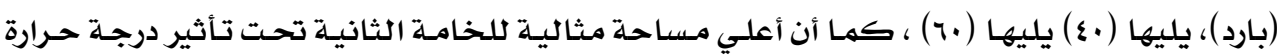

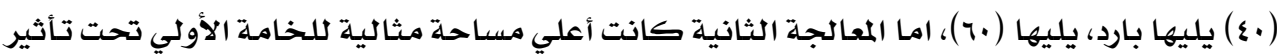

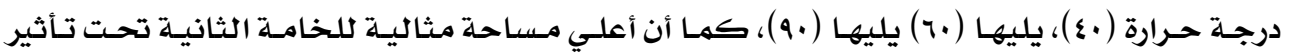

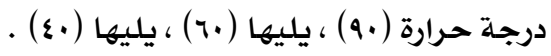

الاقدمة والمشكلة البحثية : المراهية

تعتمد جودة الأداء الوظيفى لأى نوع من الأقمشة على مايتوفر فيها من الخواص الطبيعية

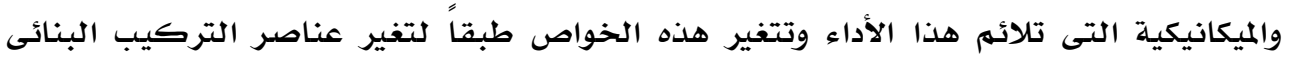

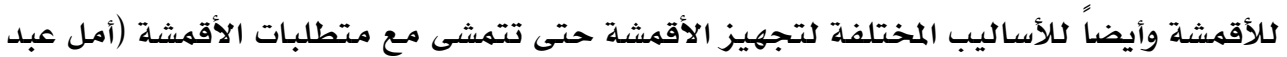

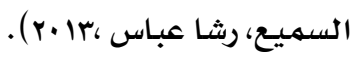

فالأقمشة القطنية هى التى يفضل استخدامها في الملابس الداخلية والخارجية والمفروشات

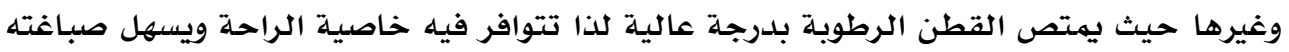

" أستاذ الملابس و النسيج بقسم الأقتصاد المنزلى * 
ويتحمل القطن المواد المؤكسلدة إلا انه ينبغى استخلدامها بعناية وهناك الكثير من المميزات الأخرى

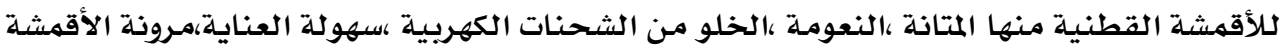

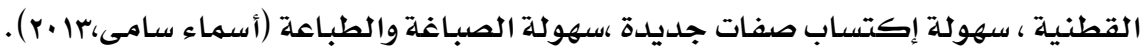
ولكن تحتوى الأقمشة القطنية على شوائب طبيعية موجودة بألياف القطن علاوة على القى القئ

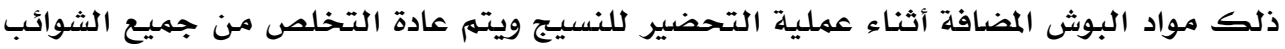

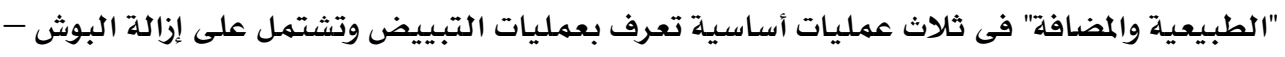

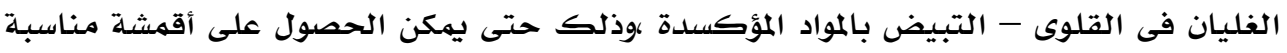

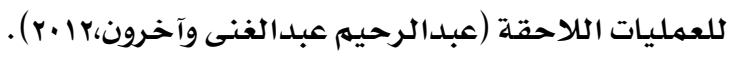
ويعتبر التبييض من العمليات التحضيريـة الأساسية فى الأقمشة التى ستمـريمراحل

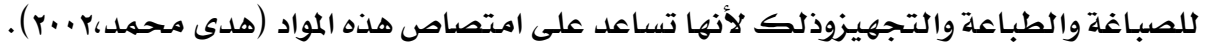
والغرض من عملية تبييض الألياف القطنية هو إزالة اللون الطبيعى الذى لا لإنيكن

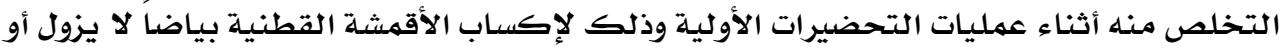

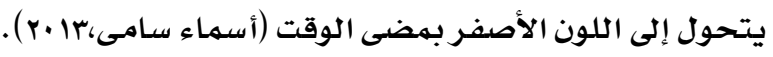

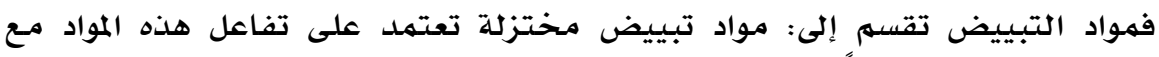

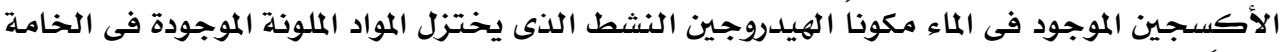

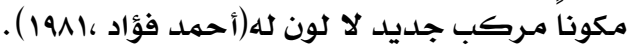

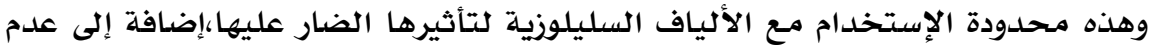

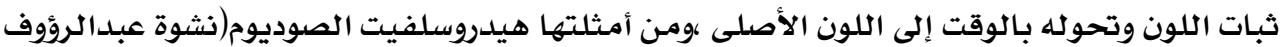
. (r..r، بينما مواد التبييض المؤكسدة تعتمد على تكوين الأكسجين النشط للتفاعل مـع المواد

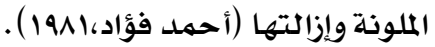
حيث تؤكسد المواد الملونة إلى مواد بسيطة ذائبة بدون لون لذا يكون بياضها ثابت،ومن

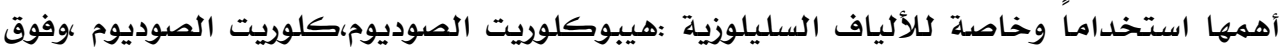

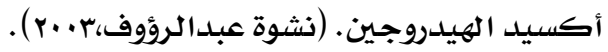
ومن الدراسات التى اهتمت بعملية التبييض دراسة (أسماء سامى،با.بr) والتى هدفت إلى

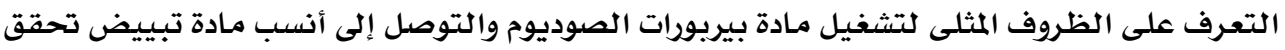

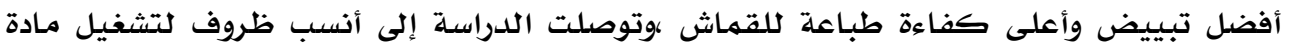

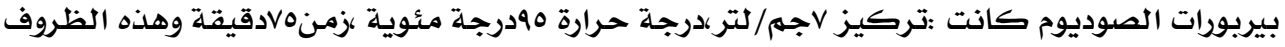

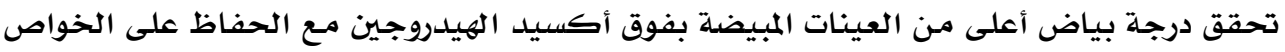

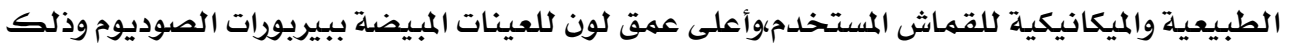




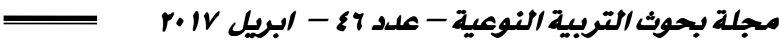

لتحسن الإمتصاص فى العينات المبيضة ببيربورات الصوديوم مقارنة بالعينات المبيضلة بفوق أكسيد

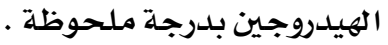

كما اهتمت دراسة (رانيا محمد ، Y.PV)بتحسين خواص الأقمشة السليلوزية المستخدمة

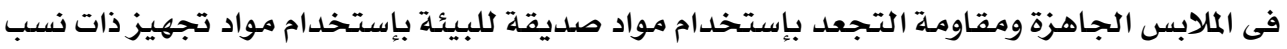

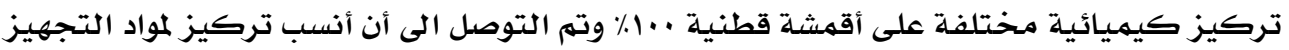

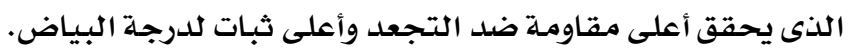

\section{ومن هنا كانت مشكلة البحث فى التساؤلات الآتية:}

ا. هل يوجد فرق بين أنواع مواد التبيض الموجودة فى السوق المحلى من حيث تأثيرها على المي

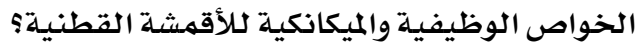

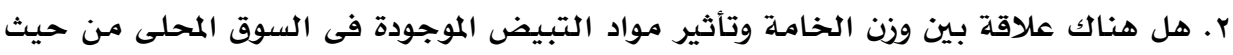

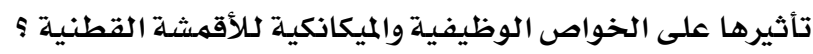

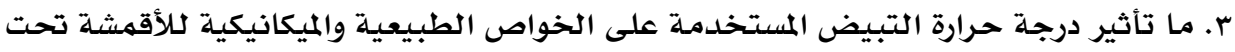

أهداف البحث :- (1)

ا ـ التوصل إلى أفضل مادة تبيض موجودة فى السوق المحلى(موضع البحث) تحقق أعلى كفاءة تبيض للقماش تحت البحث. r. التعرف على تأثير درجات الحرارة المختلفة فى عملية التبيض على الخواص التهات الطبيعية والميكانيكية للقماش تحت البحث.

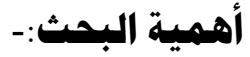

ا ـ إستخدام الأسلوب العلمى فى التعرف على الظروف المثلى لتشغيل مادة الكلور فى عملية

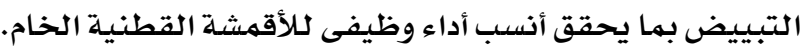

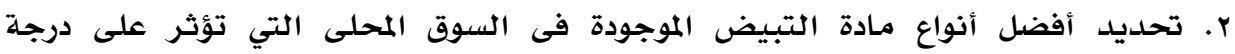

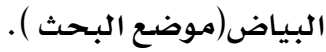
فروض البحث :ا- يوجد تأثير ذو دلالة إحصائية بين تغير المحالجات والخواص الطبيعية والميكانيكية للأقمشة محل البحثث. r- توجد علاقة بين نوع المعالجة وأفضلية الإستخدام مـع الأقهشة محل البحث.

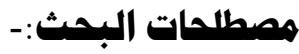

عملية التبيض Bleaching :

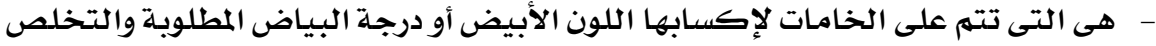

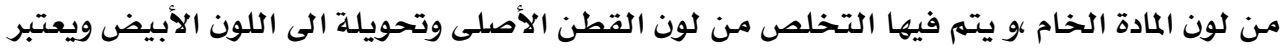


التبييض من العمليات التحضيرية الأساسية فى الأقمشة التى ستمر بمراحل الصباغة والطباعة

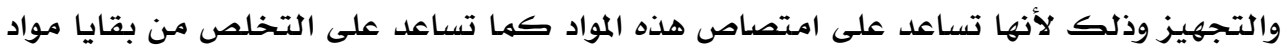

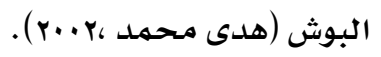

ويقصد بها ازالة اللون الطبيعى للألياف وتحويله إلى لون أبيض ثابت وذلك بتحليل

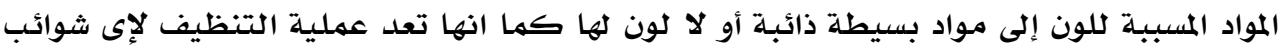

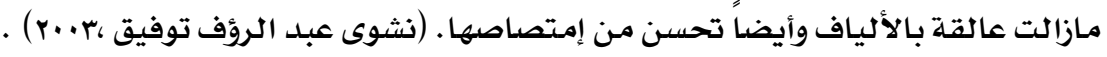

$$
\text { التعريف الإجرائى لعملية التبيض: }
$$

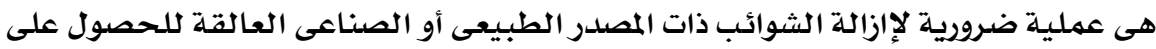

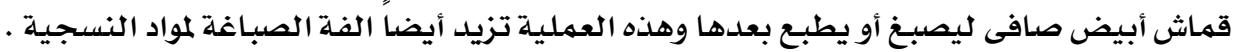

الأقششة القطنية Cotton fabrics

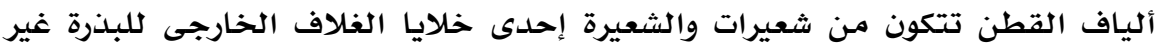

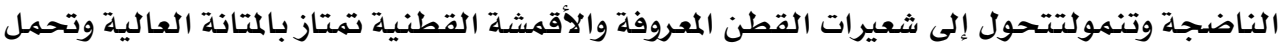

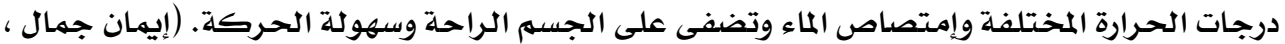

\section{التعريف الإجرائى كلأقمشة القطنية :}

الأاقمشة القطنية هى من الأقمشة الشائعة الإستخدام فى الملابس الداخلية والبياضات

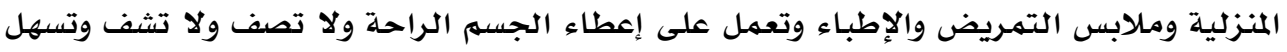

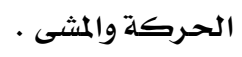
هدود البمث : nمث

- - مكانية : شركة المحلة الكبرى للغزل والنسيج

$$
\text { - نوعية : }
$$

ـ الخامات

\begin{tabular}{|c|c|c|c|c|c|c|c|c|c|c|c|c|}
\hline \multirow{2}{*}{ النسجيب التركيب } & \multirow{2}{*}{ البياض } & \multicolumn{2}{|c|}{ الإستطالة } & \multicolumn{2}{|c|}{ قوة الشد بالكجهم } & \multirow{2}{*}{ وزن المتر المربع } & \multicolumn{2}{|c|}{ نمرة الخيط } & \multicolumn{2}{|c|}{ عددقتل السم } & \multirow{2}{*}{ العرض } & \multirow{2}{*}{ نوع القماش } \\
\hline & & لحمة & 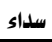 & لحعة & 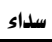 & & لحمة & 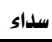 & لحمة & 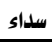 & & \\
\hline سادة & rr & r. & ro & $\llbracket \xi$ & $\leqslant \wedge$ & 19. & $1 / r$. & $1 / r$. & $r \xi$ & $r \xi$ & 107,0 & قطن.• / خام(ا) \\
\hline $1 / 1$ & H & r. & ro & 07 & $7 \varepsilon$ & lar & $1 / 17$ & $1 / 17$ & $r \xi, 0$ & ro & 10. & قطن.•1٪ خام(ז) \\
\hline
\end{tabular}

$$
\text { أ. الأقمشة ( قطن ... إمام) }
$$

جدول (1)مواصفات الأقمشة 


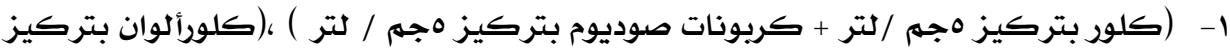

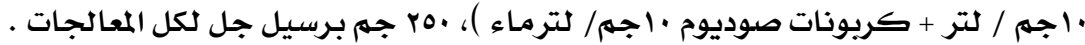

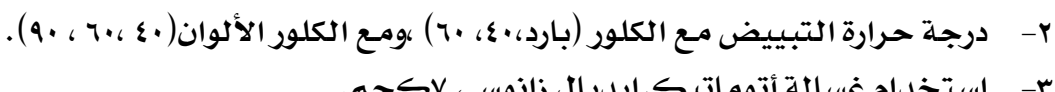

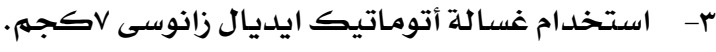

منهج البمث:إجراءات البحث:-

1- تم شراء صنفان من القماش من شركة المحلة قطن - . 1٪خام.

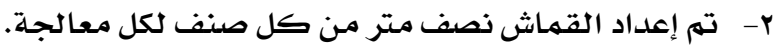

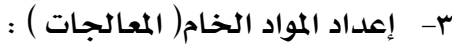

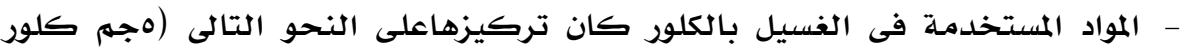

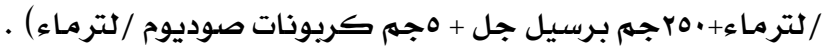

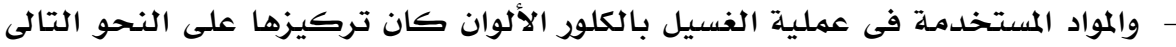

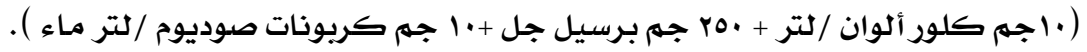

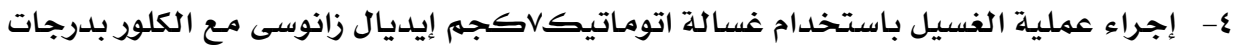

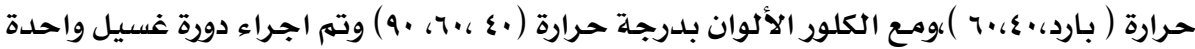

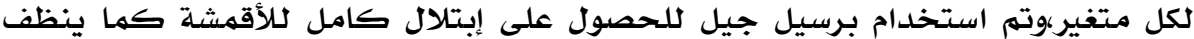

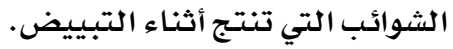

ه- إجراء عملية التجفيف بالطريقة التقليدية ( ضوء التباء التيديف الشمس ).

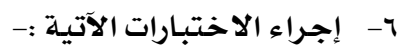

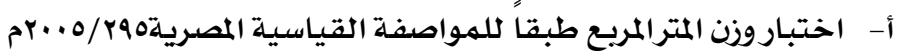

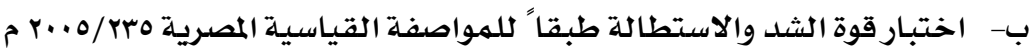

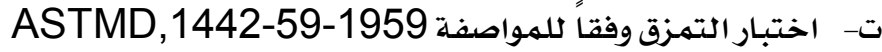

ثatacolor/Spectro Photometer . ث- اختبار درجه البياض باستخدام جهاز SF600+,DataColorInternational1994,U.S.A

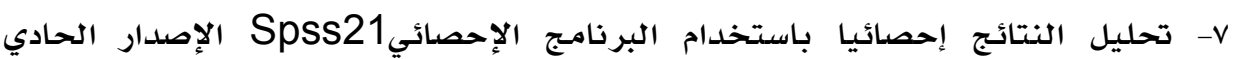

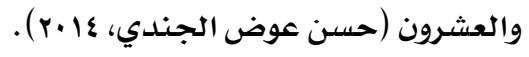




\section{بالتيرطرق التبييض المنزلية على الخواص الطبيعية والميكانيكية للأقمشة القطنية

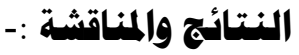

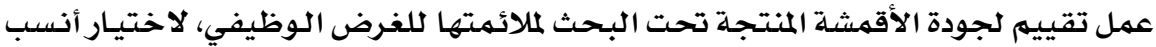

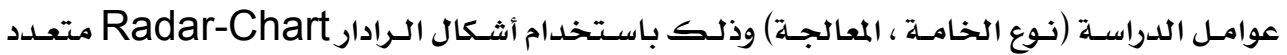

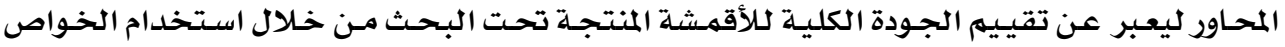

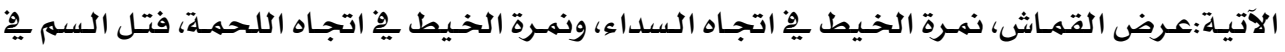

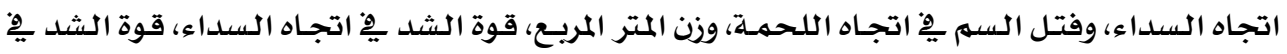

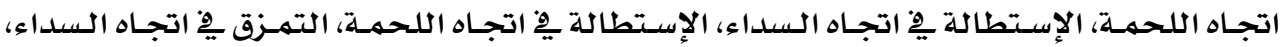

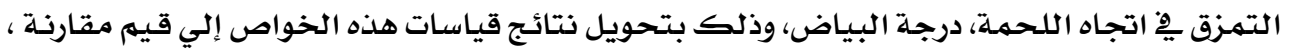

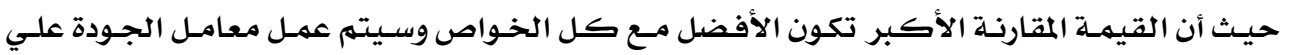

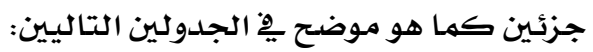

أوملا: مهمالبة (1)

جدول (Y) معامل الجودة للخواص الميكانيكة للأقمشة فِّ ضوء متغيرات البحث

\begin{tabular}{|c|c|c|c|c|c|c|c|c|c|c|c|c|c|c|}
\hline درجة البياض & |التمزق & |التمزق & |الاستطالة & |لاستطالة & قوة الشد & قوة الشد & وزن المتر & | قتل السم & |قتل السم & الخمرة & لنهرة & عرض القماش & درجة الحرارة & | الخامات | \\
\hline 36.78 & 60.53 & 62.50 & 61.54 & 76.92 & 60.53 & 62.50 & 82.61 & 96.00 & 92.31 & 100.00 & 100.00 & 100.00 & بلدون & \multirow{4}{*}{ الأولى } \\
\hline 96.55 & 52.63 & 55.00 & 76.92 & 84.62 & 52.63 & 55.00 & 80.43 & 96.00 & 100.00 & 100.00 & 100.00 & 93.61 & بارد & \\
\hline 97.70 & 42.11 & 55.00 & 76.92 & 76.92 & 42.11 & 55.00 & 76.09 & 96.00 & 100.00 & 100.00 & 100.00 & 93.93 & |درجة حرارة (•) & \\
\hline 98.85 & 31.58 & 60.00 & 69.23 & 76.92 & 31.58 & 60.00 & 78.26 & 100.00 & 96.15 & 100.00 & 100.00 & 93.61 & | درجة حرارة (•)) & \\
\hline 35.63 & 73.68 & 80.00 & 61.54 & 76.92 & 73.68 & 80.00 & 83.48 & 96.00 & 92.31 & 80.00 & 80.00 & 90.73 & بلدون & \multirow{4}{*}{ |الخامة } \\
\hline 97.70 & 100.00 & 100.00 & 100.00 & 100.00 & 100.00 & 100.00 & 93.48 & 100.00 & 98.08 & 80.00 & 80.00 & 93.61 & بارد & \\
\hline 98.85 & 89.47 & 95.00 & 100.00 & 100.00 & 89.47 & 95.00 & 100.00 & 100.00 & 96.15 & 100.00 & 100.00 & 93.93 & |درجة حرارة (•؛) & \\
\hline 100.00 & 73.68 & 75.00 & 84.62 & 92.31 & 73.68 & 75.00 & 95.65 & 100.00 & 96.15 & 100.00 & 100.00 & 93.61 & درجة حرارة (•)) & \\
\hline
\end{tabular}




\begin{tabular}{|c|c|c|c|}
\hline يرات البحث & انيكة لكلأقمث & احة المثالية لل & جدول (r \\
\hline الترتيب & المساحة المثالية & درجة الحرارة & الخامات \\
\hline & 17622.87 & بلدون & \multirow{4}{*}{ الخامة الأولى } \\
\hline 1 & 18268.01 & بارد & \\
\hline 2 & 17128.84 & درجة حرارة (•) & \\
\hline \multirow[t]{2}{*}{3} & 16477.11 & درجة حرارة (†) & \\
\hline & 17388.85 & بلدوز & \multirow{4}{*}{ الخامة الثانية } \\
\hline 2 & 25052.11 & بارد & \\
\hline 1 & 25777.66 & درجة حرارة (•) & \\
\hline 3 & 22130.97 & درجة حرارة (•") & \\
\hline
\end{tabular}

تثير نتائج الجدول السـابق أن أعلي مساحسة مثالية للخامة الأولي تحت تأثير درجة حرارة

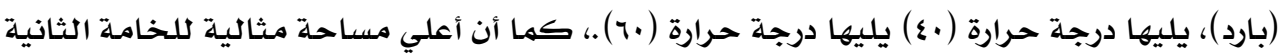

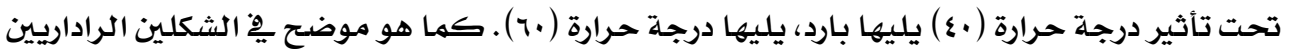

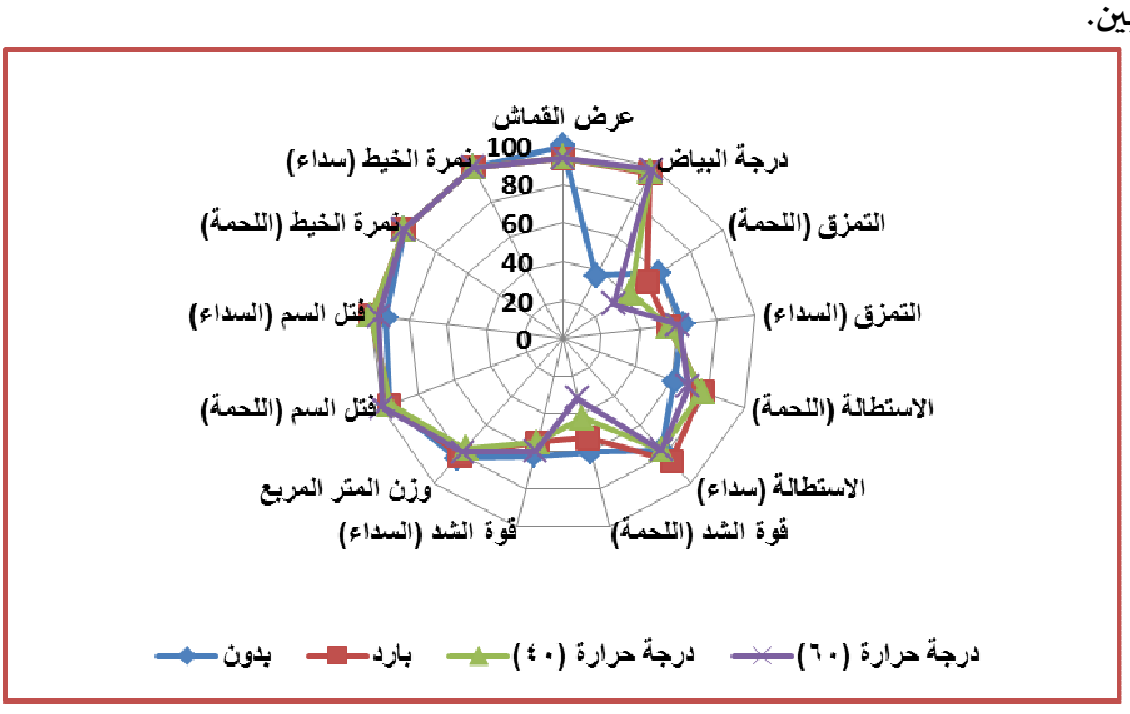

شكل (1) يوضح تأثير المعالجة الأولي علي الخواص الطبيعية والميكانيكية للخامة الأولي باختلاف درجات الحرارة. 


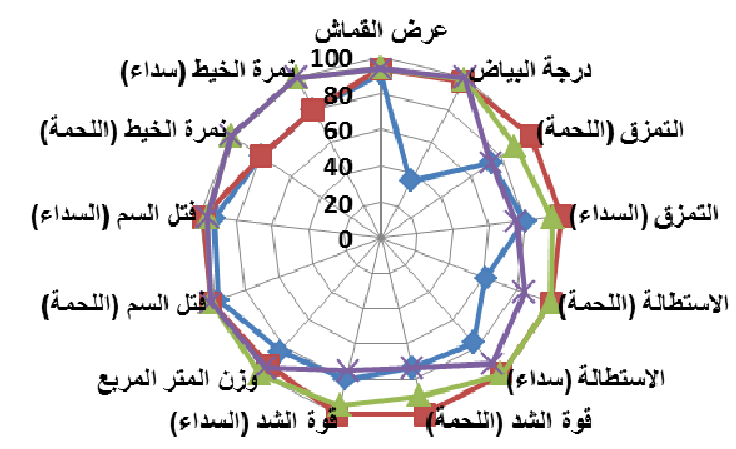

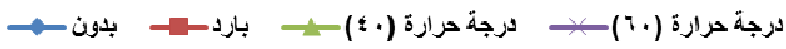

شكل (r) يوضح تأثير المعالجة الأولي علي الخواص الطبيعية والميكانيكية للخامة الثانية

باختلاف درجات الحرارة.

(v) ثلنيا: همالبة

جلدول (ع) معامل الجودة للخواص الميكانيكية للأقمشة ِِ ضوء متغيرات البحث

\begin{tabular}{|c|c|c|c|c|c|c|c|c|c|c|c|c|c|c|}
\hline |لبياض & |التمزق & |التمزق & الاستطالة & |الاستطالة | (سلاء) & قوة الشد & قوة الشد & وزن المتر & (السلم & قلس & الخمرة & | لنغرة & عرض & درجة الحرارة & |الخامات | \\
\hline 34.78 & 74.19 & 73.53 & 72.73 & 90.91 & 74.19 & 58.14 & 79.17 & 96 & 92.31 & 100 & 100 & 100.00 & بلدون & \multirow{4}{*}{ الخألى } \\
\hline 97.83 & 77.42 & 76.47 & 90.91 & 100.00 & 77.42 & 60.47 & 75.00 & 96 & 96.15 & 100 & 100 & 92.65 & درجة حرارة (•) & \\
\hline 96.74 & 77.42 & 58.82 & 90.91 & 90.91 & 77.42 & 46.51 & 75.00 & 100 & 100 & 100 & 100 & 92.97 & درجة حرارة (•") & \\
\hline 98.91 & 64.52 & 61.76 & 90.91 & 90.91 & 64.52 & 50.00 & 75.00 & 100 & 100 & 100 & 100 & 92.65 & درجة حرارة (*9) & \\
\hline 33.70 & 90.32 & 94.12 & 72.73 & 90.91 & 90.32 & 74.42 & 80.00 & 96 & 92.31 & 80 & 80 & 90.73 & بلدون & \multirow{4}{*}{ الثالثة الثانية } \\
\hline 88.04 & 90.32 & 91.18 & 90.91 & 90.91 & 90.32 & 72.09 & 66.67 & 98 & 98.08 & 80 & 100 & 92.65 & درجة حرارة (•) & \\
\hline 95.65 & 100.00 & 100.00 & 100.00 & 100.00 & 100.00 & 100.00 & 100.00 & 100 & 100 & 80 & 80 & 9.27 & درجة حرارة (•7) & \\
\hline 100.00 & 87.10 & 91.18 & 90.91 & 90.91 & 87.10 & 72.09 & 95.83 & 100 & 100 & 100 & 100 & 92.65 & درجة حرارة (•9) & \\
\hline
\end{tabular}


مجلة بحوث التربية النوعية - علد باء - ابريل r.IV

جدول (0) المساحة المثالية للخواص الميكانيكة للأقمشة يٌْ ضوء متغيرات البحث

\begin{tabular}{|c|c|c|c|}
\hline الترتيب & المساحة المالية & درجة الحرارة & الخخامات \\
\hline & 19036.84 & بلدون & \multirow{4}{*}{ الخامة الأولى } \\
\hline 1 & 21255.39 & درجة حرارة (•) & \\
\hline 2 & 20345.57 & درجة حرارة (•7) & \\
\hline \multirow[t]{2}{*}{3} & 19597.38 & درجة حرارة (a) & \\
\hline & 19198.52 & بلدوز & \multirow{4}{*}{ الخامة الثانية } \\
\hline 3 & 21354.83 & درجة حرارة (•) & \\
\hline 2 & 23726.61 & درجة حرارة (†) & \\
\hline 1 & 23762.95 & درجة حرارة (•a) & \\
\hline
\end{tabular}

تشير نتائج الجدول السابق أن أعلي مساحة مثالية للخامة الأولي تحت تأثير درجة حرارة

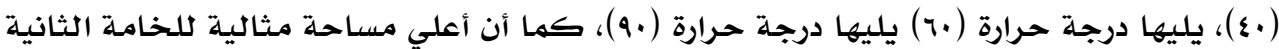

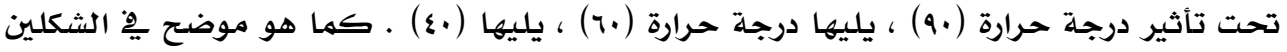
الراداريـين التاليين.

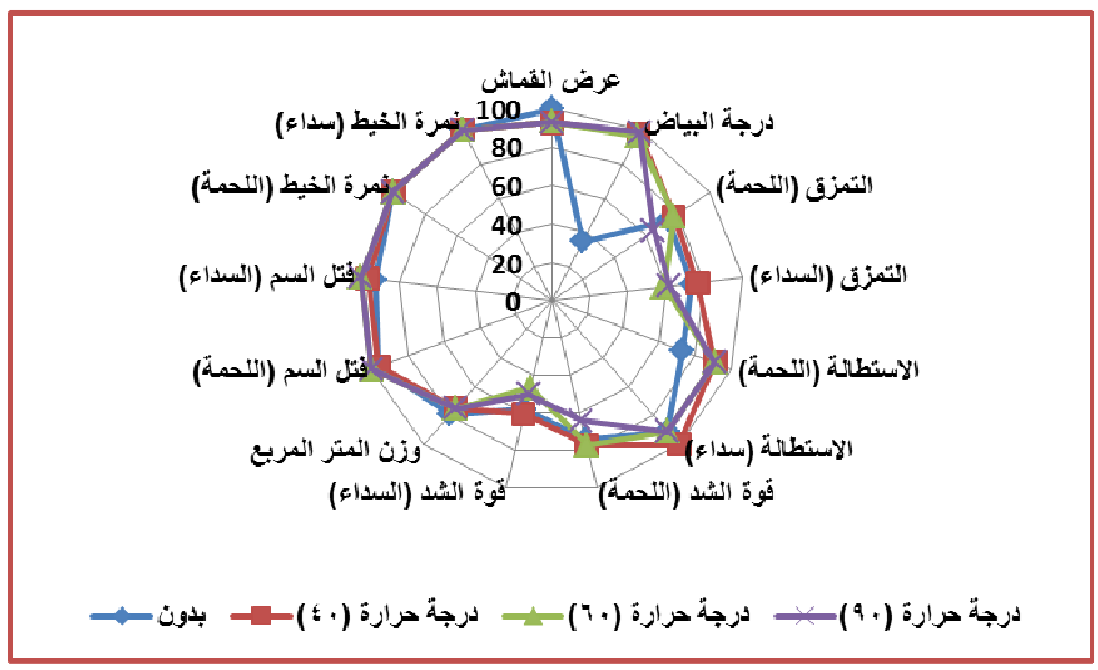

شكل (r) يوضح تأثير المعالجة الثانية علي الخواص الطبيعية والميكانيكية للخامة الأولي باختلاف درجات الحرارة. 


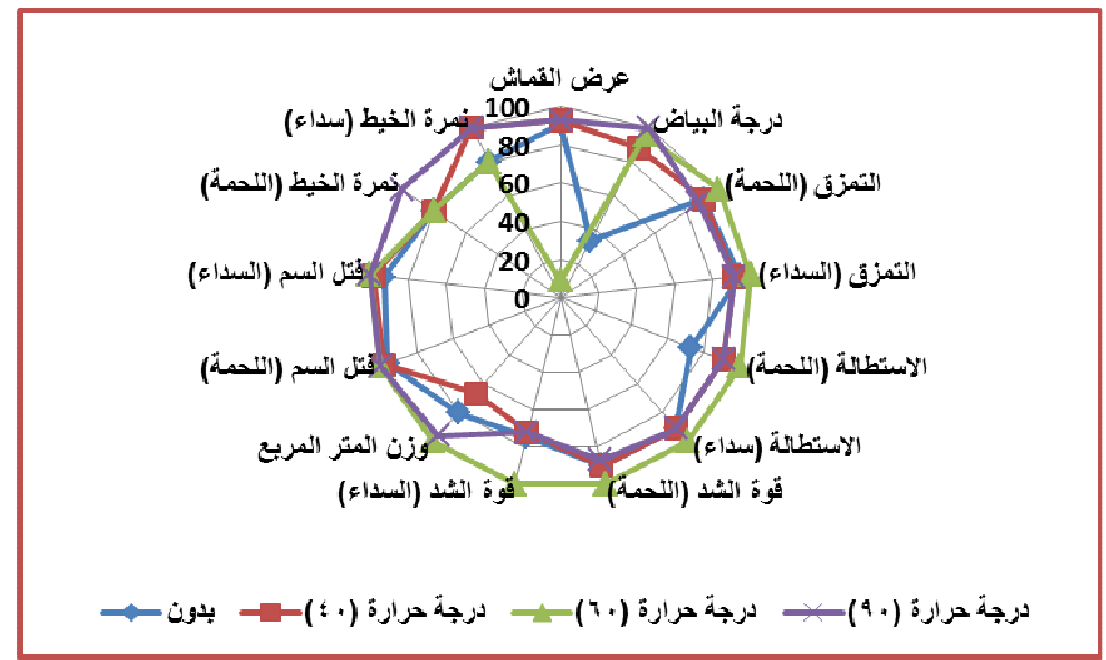

ثكل (ع) يوضت تأثير المعالجة الثانية علي الخواص الطبيعية والميكانيكية للخامة الثانية باختلاف درجات الحرارة.

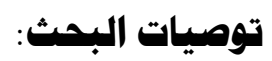

ا ـ الاهتمام بتدريس مواد التبييض لطالبـات كلية التربية النوعية بما يتوافق مـع المنتج الملبسى.

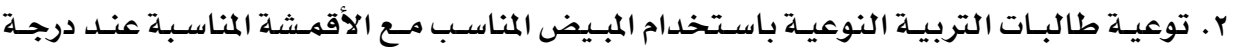
الحرارة المناسبة.

r. مواصلة التجارب العلمية لإنتاج مبيضات للأقمشة ذات مواصفات أفضل امـا بتعديل المنتجات

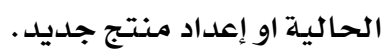

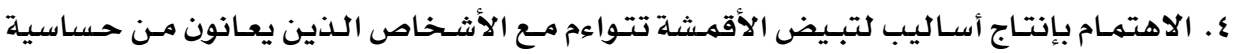

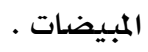
ه. التوسـع ِِّ استخدام المبيضات الطبيعية والعمل على تطوير أسواقها لكونها ذات تأثير اقل على الع جودة الأقمشة. 7. التوسـع ِِّ دراسة تأثير التبييض بالكلور على باقي خواص الأداء الوظيفي للأقمشة .

ا. الهيئة المصريـة العامـة للمواصفات والجـودة: الطـرق القياسـية لتقدير طول وعـرض ووزن وسمـك الأقمـشة

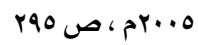

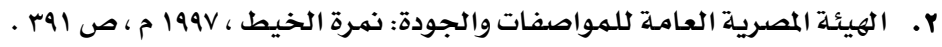

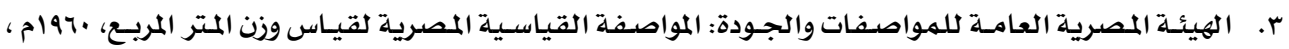
ص ع. الهيئة القومية العامـة للتوحيد القياسي : قوة الشد والاستطالة وفقاً للمواصفة القياسية هrr/ه ..rم 
مجلة بحوث التربية النوعية - علدد r - ابريل r.IV

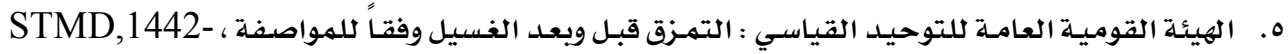

T. الهيئة القومية العامـة الهيئة المصرية العامـة للتوحيد القياسى فى المواصفات القياسية المصرية: " تقدير

درجة البياض والعتامة للورق" رقم .09 لسنه 1970.

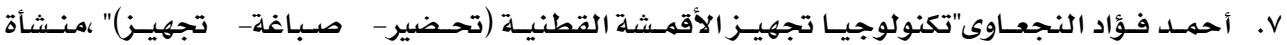

المعارف،الإسكندرية ، 1911 ام.

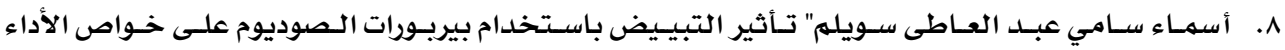

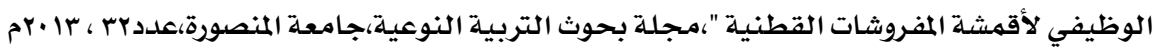

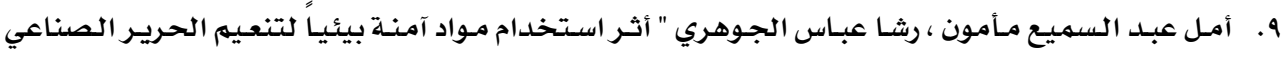

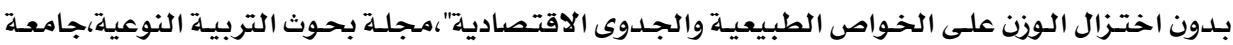

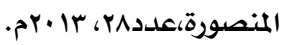

• ا ـ إيمان جمال غزى "تأثير بعض المواد المنظفـة على خـواص الأقمهشة القطنية وخلطاتها"، رسـالة ماجستير

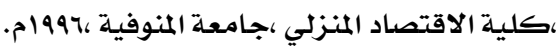

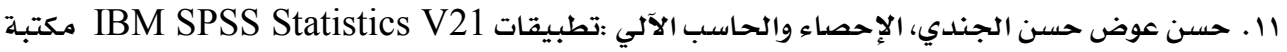

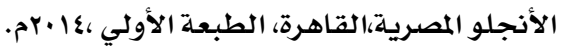

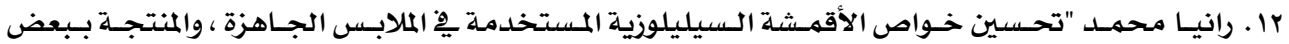

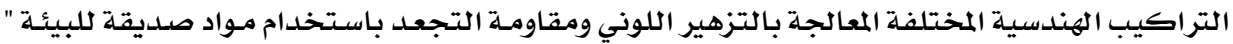

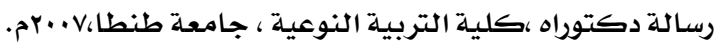

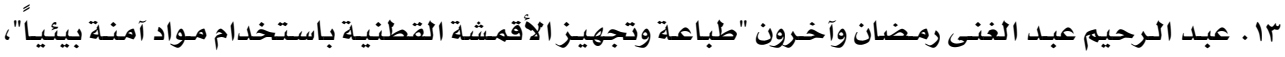

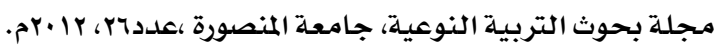

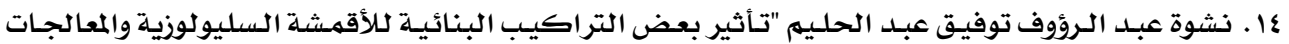

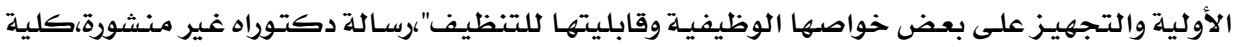

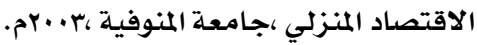

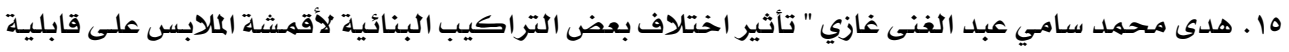

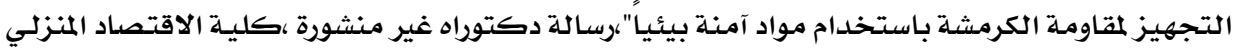

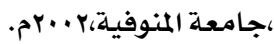




\section{Effects of Domestic Bleaching Methods on Natural and Mechanical Characteristics of Cotton Textiles}

\section{Abstract}

The study aims at finding the best bleaching agent available in local market (under study) that achieves the highest bleaching efficiency for textiles in question, and identifying the effect of different temperatures used in the bleaching process on natural and mechanical characteristics of textiles under study.

Having carried out statistical analysis, the most important results are as follows:

In first treatment, maximum optimized area for first material was obtained under the effect of temperatures: (cold), then (40), then (60); and maximum optimized area for second material was obtained under the effect of temperatures: (40), then cold, then (60). As for second treatment, maximum optimized area for first material was obtained under the effect of temperatures: (40), then (60), then (90). Moreover, maximum optimized area for second material was obtained under the effect of temperatures: (90), then (60), then (40). 